\title{
The effects of SRT, OLR and feed temperature on the performance of membrane bioreactor treating high strength municipal wastewater.
}

\begin{abstract}
The effects, of sludge retention time (SRT), feed temperature (Tf) and organic loading rate (OLR) on submerged membrane bioreactor (SMBR) performance were studied using hollow fibers (nominal pore size $0.4 \mu \mathrm{m}$ ) immersed in an aeration tank. A synthetic wastewater representative of high strength municipal wastewater was used in the study. Ten experimental runs were carried out using full factorial design with three factors and three levels (low, medium and high). These levels were 25, 30 and 35 days for SRT, 20, 30 and $40^{\circ} \mathrm{C}$ for $\mathrm{Tf}$ and $1.73,4.03$ and $6.82 \mathrm{~kg} \mathrm{COD} / \mathrm{m}^{3} \mathrm{~d}$ for OLR. Variation of OLR, SRT and Tf affected the biomass development significantly. The higher OLR trials resulted in higher MLVSS/MLSS ratio and also higher increasing rate of MLSS (d(MLSS)/ (dt)). For the low level OLR trials MLVSS/MLSS ratio varied between 75.3 and $82.3 \%$ and d(MLSS)/(dt) from 87.5 to 297.3 $\mathrm{mg} / \mathrm{l} . \mathrm{d}$, whereas, for the high OLR trials they varied between 80.4 and $83.7 \%$ and $1355.4-$ $2120.1 \mathrm{mg} / \mathrm{l} . \mathrm{d}$ respectively. For the higher OLR, a higher aeration rate was applied to fulfill the DO demand. Therefore, for the low level OLR trials, the aeration rate and the DO were varied from 6 to $12 \mathrm{~m}^{3} / \mathrm{m}^{2}$ membrane area per hour and from 3.7 to $5.7 \mathrm{mg} / \mathrm{l}$, respectively, whilst for the high OLR trials they varied from 6 to $18 \mathrm{~m} 3 / \mathrm{m}^{2}$ membrane area/h and from 0.9 to $4.4 \mathrm{mg} / \mathrm{l}$ respectively. The permeate COD and NH3-N under different operating conditions varied from 0 to $32 \mathrm{mg} / 1$, and from 0.004 to $0.856 \mathrm{mg} / \mathrm{l}$, respectively. The interaction effects of SRT and Tf on COD removal efficiency was found to be insignificant. Increasing OLR did not affect COD removal. The optimum removal efficiency of ammonia nitrogen for the low and high strength wastewater was obtained at operating conditions of high SRT and low Tf. The $\mathrm{pH}$ increased significantly in the aeration tank and the increase was well correlated with the feed $\mathrm{pH}\left(\mathrm{r}^{2}=0.8336\right.$ for low OLR and 0.9106 for high OLR $)$.
\end{abstract}

Keyword: Membrane bioreactor; Synthetic wastewater; Organic loading rate; MLSS development; COD removal. 